\title{
LA CRISIS FILOXERICA EN ESPAÑA (ESTUDIO COMPARATIVO SOBRE LAS CONSECUENCIAS SOCIO-ECONOMICAS DE LA FILO. XERA EN ALGUNAS REGIONES VITTVINICOLAS ESPAÑOLAS)
}

por

ANDREAS OESTREICHER

Instituto de Estudios Riojanos.

RESUMEN: La filoxera, el insecto microscópico que atacó y arrasó los vinedos europeos a finales del siglo pasado, invadio España en el año 1878, al aparecer su primer foco en la provincia andaluza de Malaga. A partir de esta fecha extendió su marcha funesta por todas las provincias vitivinicolas españolas, causando la destrucción de casi la totalidad de los viñedos de la Península y llevando a la más completa miseria a cientos de miles de viticultores. Existen, sin embargo, apreciables diferencias entre las respectivas regiones vitivinicolas españolas en cuanto a las consecuencias socio-económicas de esta plaga y, también, a las respuestas adoptadas frente a ella, ya sea respecto a la lucha antifiloxérica o a las medidas emprendidas para salir de ella. Apreciar y analizar estas diferencias será el objetivo del presente artículo que tendrá en cuenta, principalmente, las regiones de La Rioja, Cataluña y partes de Andalucía.

Palabras Clave. Vitivinicultura española, crisis floxérica, lucha antifiloxérica, replantación, consecuencias sacio-económicas, cambios estructurales.

\begin{abstract}
Phylloxera, a microscopic insect which destroyed European vineyards at the end of last century, invaded Spain in 1878. The first outcrop of this pest was discovered in the Andalusian province of Malaga and soon spread to all Spanish wine regions, causing the distruction of practically all the vineyards in the Pentnsula and ruining hundred thousands of wine growers. There are, however, appreciable differences in the socio-economic effect of this pest on the various regions. These differences are also reflected in the steps taken at the time, both in fighting against phylloxera as well as in the measures taken to overcome the disaster. This article evaluates and analyzes these differences in the regions of Rioja, Catalonia and parts of Andalusia.
\end{abstract}

KEY WORDS: Spanish viticulture, phylloxera, fight against phylloxera, replanting, socio-economic consequences, structural changes.

Hispania, LV12, núm. 193 (1996) 587.622 


\section{INTRODUCCION}

Es asombrosa la laguna que existe en la historiografía española referente a la crisis filoxérica en España, tanto a nivel regional, como a nivel nacional. Más aun si tenemos en cuenta que se trata de una crisis que afectó a una parte muy grande de la geografía española y que proporciona al historiador un instrumento extraordinario para analizar comparativamente diferentes tendencias, sean sociales, sean económicas o agrarias, en numerosas regiones españolas.

Entre las pocas excepciones que sí han tomado en consideración la filoxera y sus consecuencias, podemos destacar dos tendencias: una sobrevalora de manera exagerada el impacto social y económico de esta crisis, asignándole una responsabilidad demasiado directa sobre los cambios y tendencias socioeconómicas de una región, al desatender otros factores de suma importancia. Otra infravalora la crisis filoxérica, concediéndole un espacio meramente marginal en el análisis de los hechos históricos.

El debate sobre las consecuencias de la plaga filoxérica está, sin embargo, y a pesar de su poca intensidad, vivo. Un debate que surgío, quizá, con el excelente libro de M. ${ }^{a}$ Teresa Carnero i Arbat ${ }^{1}$, en el que comparó las respuestas contra la filoxera en Cataluña y el País Valenciano con las que se adoptaron en Málaga, y que llevó a una cierta polémica muy fructífera entre historiadores de las dos regiones.

Otras aportaciones recientes y menos recientes han contribuido a desmitificar en buena medida lo ocurrido alrededor de la filoxera y han dado pasos importantes a llevarla al sitio histórico que le corresponde ${ }^{2}$. Ahora es quizá el momento de intentar una síntesis.

La idea ha surgido a raíz de mi tesis doctoral, que está en vías de realización, sobre las consecuencias socio-económicas de la crisis filoxérica en la entonces llamada Provincia de Logroño. Estas investigaciones me llevaron a buscar estudios con la misma temática sobre otras provincias vitivinícolas españolas, para evitar conclusiones demasiado restrictivas y, por ello, erróneas, situando lo específicamente riojano dentro de un marco geográfico más amplio. El estudio de estos trabajos ha sido muy fructifero porque me ha dado la oportunidad de trabajar comparativamente, es decir, de relacionar tendencias similares y discrepantes en otras regiones y de analizar el porqué de éstas.

Se llega así a la conclusión de que el impacto social y económico de la filoxera no se puede apreciar sin tener en cuenta la determinada fase histórica de una región en el momento de ser invadida por este insecto destructor. Por fase histórica determinada entiendo una realidad histórica amplia que se refiere

1 CARnERo I ARBat, T., (1980), Expansión vinícola y atraso agrario, Madrid. GuISADo López, J. M., (1983), «Crisis agraria e invasión filoxérica en la España del siglo XIX», Revista de Historia Económica, ẫo 1, núm. 2, págs. 165-184.

2 Ver bibliografia y notas de pie de página siguientes.

Hispania, LVI2, núm 193 (1996) 587-622 
tanto a la evolución socio-económica de esa región y al momento en que ésta se ve interrumpida o censurada por la aparición de la filoxera, como a las coyunturas externas e internas que influyen sobre ella.

En los siguientes capitulos intentaré, por lo tanto, determinar, en primer lugar, los factores decisivos que llevaron en cada región a respuestas concretas ante la crisis filoxérica y, en segundo lugar, llegar a una vision sintetizadora de la crisis que tenga en cuenta todos estos factores. Las regiones examinadas serán La Rioja, Cataluña y partes de Andalucía, no sólo por su representatividad dentro del marco histórico español, sino también por existir sobre estas regiones una bibliografía más extensa ${ }^{3}$.

\section{LA LUCHA ANTIFHOXERICA}

La filoxera, descubierta por primera vez en 1863 en un invernadero de una localidad cercana a Londres, hizo su entrada en el continente europeo entre este mismo año y 1867 , al aparecer en varias provincias vitivinícolas francesas de Gironde, Provence y Languedoc ${ }^{4}$. No fue, sin embargo, identificada como tal hasta julio de 1868 .

En España, la prensa empeź́ muy pronto a interesarse por esta nueva plaga, seguida por la administración que ya en 1872 dictó la primera orden ministerial relativa a la filoxera y envió poco después una circular a los gobernadores pidiendo información sobre la existencia de la plaga y, en caso de su existencia, muestras de cepas infectadas.

Siguio, en el afio 1874, la prohibición de importar vides y sarmientos procedentes de los estados filoxerados y, un afio más tarde, se puso en marcha un plan antifiloxérico que contenía, como primera medida, el envío de una delegación a Francia con el fin de ampliar la información y los conocimientos acerca del insecto. Se distribuyó también una hoja volante por todo el estado con dibujos de la filoxera y la descripción de los signos exteriores de una vid afectada por ella.

A pesar de estas primeras medidas y pasando por alto la contundente afirmación de algunos sectores que negaron categóricamente la posibilidad de una invasión filoxérica en la Península, el primer foco de la temible plaga aparecíb en terreno español en 1878 en la provincia de Málaga, como consecuencia de la adquisición de cepas americanas, cuatro años antes, por un viticultor malagueño. Casi al mismo tiempo, la filoxera hizo su entrada también desde Francia, invadiendo Cataluña por la provincia fronteriza de Gerona. A partir de ahí, la plaga se extendió por toda la Península, lenta pero progresivamente, atacando provincia por provincia, como se aprecia muy bien en el siguiente mapa.

\footnotetext{
3 Ver bibliografia.

4 Sobre la filoxera en Francia: Pouget, R, (1990), Histoire de la lutte contre le Phylloxéra de la vigne en France. Versailles: Institut Nacional de la Recherche Agronomique.
} 
No queremos detallar ahora las medidas adoptadas por el estado para luchar contra la plaga, que se podrían calificar, al menos en el papel, de bastante radicales y defensivas, pero de escaso éxito a causa de la crónica falta de fondos. Existían contradicciones enormes entre los medios econ6micos disponibles y los instrumentos de lucha propuestos por la administración ${ }^{5}$.

El mayor peso de la lucha antifiloxérica cayó plenamente sobre las provincias, por lo que intentaremos seguir su evolucion en las provincias y regiones que nos interesan.

\section{I.1. Provincia de Logroño}

La provincia de Logroño fue invadida por la filoxera en el año 1899, es decir, comparativamente tarde. Su historia relacionada con la plaga se inició, sin embargo, bastante antes, en el año 1878 , cuando se constituyó en dicha provincia la Comisión Provincial de Defensa contra la Filoxera, una de las primeras del estado español. El 30 de noviembre del mismo año dicha comisión dirigió un informe al Director General de Instrucción Pública, Agricultura e Industrias en el que informaba sobre lo siguiente:

"Se ha acordado una medida de la mayor importancia para remediar los estragos del mal si desgraciadamente se presentase. Tal es, el establecimiento de tres viveros de simiente de vides resistentes a la filoxera, situados respectivamente en las comarcas que se conocen por Rioja Alta, Media y Baja.. ${ }^{6}$

Respecto a trabajos de divulgación, se organizo en la capital un ciclo de conferencias sobre la plaga con el especialista José Muñoz de Castillo, las cưales fueron publicadas posteriormente ${ }^{\text {? }}$.

Pero el comienzo fulminante de esta comisión muy pronto dejo lugar a una inactividad absoluta, que duró hasta 1896 , año en que en la vecina provincia de Navarra fue oficialmente declarada la invasión filoxérica ${ }^{8}$. La noticia cayó como un rayo en La Rioja, que la recibio totalmente desprevenida. El diario La Rioja empezó a publicar diariamente artículos que tenían la filoxera como protagonista. Sus corresponsales exigieron a la Diputacion la pronta aplicación de la ley contra la filoxera del año 1885 y, en especial, la prohibición de nuevas plantaciones de vid en la región y la supresión del comercio de cepas,

\footnotetext{
5 Las medidas antifiloxéricas del Estado Español están muy bien detalladas en: PAN MoNTojo Gonzílez, J. L., (1994), La bodega del mundo. Historia de la vid y el vino en la España contemporánea, 1900-1936, Madrid: Alianza, Ministerio de Agricultura.

6 Parte mensual de la Comisión Provincial de Defensa contra la Filoxera de Logroño dirigido al Director General de Instrucción Pública. Agricultura e Industrias, recogido en: PRovedo GonZALEZ, J., (1987), «La filloxera en la provincia de Logroño (Destrucción del viñedo y su reconstitución)», Zubia, núm. 5, pág. 153.

7 MuÑoz del Castillo, J., (1978), La plaga filoxérica. Logrỡo.

8 Los primeros focos filoxéricos parecen haber aparecido en Navarra ya en 1982.
}

Hispania, LVI/2, aúm. 193 (1996) 587-622 
puesto que existía la grave sospecha de que la filoxera había sido introducida en Navarra por la importación de material orgánico procedente de zonas filoxeradas ${ }^{9}$.

La Comisión de Defensa contra la Filoxera, ante esta situación, dictó unas disposiciones que prohibían estrictamente la plantación de viñedos nuevos sin la aprobación explícita de la misma. A la vez formó un cuerpo de especialistas encargados del reconocimiento sistemático del vifiedo riojano para detectar, cuanto antes, una eventual invasión por el insecto ${ }^{10}$. Mientras tanto, todos estaban muy pendientes de lo que estaba pasando en Navarra, donde el famoso especialista e ingeniero agrónomo Nicolás García de los Salmones había sido encargado de dirigir la lucha antifiloxérica.

Si intentamos caracterizar estos primeros años de confrontación indirecta con la filoxera en la provincia de Logroño, tenemos que destacar los siguientes hechos:

1) Gran interés por la evolución de la crisis en Navarra: «Si se salva Navarra nos salvamos todos, si no también la Rioja sucumbirá." "Todos los esfuerzos navarros de destruir el insecto o, por lo menos, de contener la plaga recibieron en La Rioja abundante aplauso. En cuanto surgio, sin embargo, el tema de la replantación del viñedo con cepas americanas, las críticas se volvieron fuertes. Esta postura un tanto egoísta tenía su lógica, puesto que la decisión de afrontar la replantación significaba al mismo tiempo el abandono de los esfuerzos defensivos y, por consiguiente, la libre propagación de la plaga. Cuando la Diputación de Navarra decidió abandonar las medidas defensivas, por ser caras e inútiles, y posibilito, apoyada por una real orden, la libre circulación de plantas americanas dentro de la provincia, La Rioja reaccionó con indignación:

"Cuanto acabamos de decir es nada en comparación del inmenso perjuicio que la Real orden del 25 de enero hace a la provincia de Logroño y a la comarca de Aragón; para no estendernos más, sin beneficiar casi en nada a Navarra, pero sí mucho a los comerciantes de vides americanas representados por el Instituto agricola Catalán; [...] y respecto a los vendedores de vides es preciso saber que son en número bastante limitado, que sus intereses representan muy poco respecto a las comarcas que se han de destruir [... ]" 12

2) Problemas en la organización interna y falta de fondos: La inactividad y la falta de preparación ante el caso de emergencia, por parte de las instituciones riojanas, tuvo sus graves consecuencias. Tanto la recaudación de fondos -el impuesto filoxérico previsto por la ley de 1885 no se llegó a cobrar nunca--, como la coordinacion de la defensa entre los municipios riojanos se

9 La Rioja, 5.11.1896.

10 La Rioja, 29.11.1896.

11 La Rioja, 21.11.1896.

12 La Rioja, 9.02.1899. 
encontraron en la práctica con enormes problemas y resultaron al fin un fracaso absoluto.

3) Déficit en la preparación de la opinión pública: Es un hecho que la sociedad riojana vinculada al sector vitivinícola no estaba preparada para afrontar el problema de la filoxera por falta de información y de sensibilización. La indiferencia, pasividad y falta de cooperación de los viticultores riojanos, tan criticadas por los medios de comunicación, fueron una de las consecuencias de esta negligencia. Es, a su vez, evidente que la larga crisis del sector vitivinícola tradicional a partir del año 1892 tampoco favorecía una actitud más colaboradora, lo cual agravó considerablemente los problemas.

Cuando el personal técnico de la Estación Enológica de Haro descubrió el primer foco filoxérico en territorio riojano en junio de 1899 la falta de preparación se evidenciaba todavía más:

«En el día de hoy se nos presenta el problema siguiente: En el pueblo de Sajazarra aparecen 4 focos filoxéricos. Según la Ley, se debe acudir e indemnizar lo que se destruya, que es lo invadido y algo más, quemando las plantas etc. Todo ello se ha de satisfacer con los fondos recaudados y beneficia a la provincia en general, directamente a Sajazarra y más principalmente todaváa a los términos inmediatos a Sajazarra, entre ellos, el de Haro.

La mayoría de estos pueblos sin embargo no han satisfecho el inpuesto del año, otros el de este año y el anterior, y algunos como Sajazarra, ninguno de los tres repartimientos hechos.» 13

Aparte de los problemas financieros que imposibilitaron cualquier iniciativa enérgica de lucha contra la filoxera, la inflexibilidad del aparato burocrático estatal y la falta de competencia propia de la administración provincial también jugaban un papel importante en el fracaso de las medidas defensivas. La dependencia del Gobierno Central a la hora de fijar el presupuesto causo unas demoras importantes, de tal forma que, por ejemplo, en 1899, ante el retraso del visto bueno por parte de la administración central, los miembros de la comisión antifiloxérica tuvieron que salir fiadores ellos mismos para adquirir el sulfuro de carbono necesario para la desinfectación de las viñas afectadas ${ }^{14}$.

La falta de cooperación por parte de los viticultores riojanos es otro dato que se ha de considerar. Los conflictos entre ellos y el personal técnico fueron cotidianos, especialmente si se trataba de tomar medidas que les afectaba materialmente. La aplicación del insecticida sulfuro de carbono y la posterior quema de las viñas afectadas, como medidas para contener la plaga, fueron rechazadas abiertamente por la mayoría de los viticultores. Las autoridades no consiguieron ni siquiera que, para no propagar la plaga, no vendimiaran en los

13 La Rioja, 8.06.1899.

I4 La Rioja, 9.06.1899.

Hispania, LV/2, nưm. 193 (1996) 587-622 
viñedos filoxerados 15 . Es evidente que a los viticultores les importaban mucho más los ingresos de una cosecha, por pequeña que fuera, que las promesas de un futuro mejor sin el más mínimo apoyo material. Además, para mantener el orden social y evitar enfrentamientos más conflictivos, nadie podía pensar en medidas más duras, impuestas a la fuerza por las autoridades.

Para entender estos hechos nos tenemos que fijar en la situación por la que pasaba el sector vitivinícola tradicional de la zona. Desde el final de las exportaciones masivas a Francia, que habian hecho crecer el cultivo de la vid de manera totalmente desproporcionada, es decir, desde el año 1892, la viticultura riojana luchaba contra una enorme crisis de sobreproducción y de depreciación de sus vinos. Unicamente la naciente industria bodeguera de vino de calidad estaba en condiciones de paliar un poco los efectos del cierre de las fronteras entre España y Francia, pero estaba muy lejos de lograrlo de manera satisfactoria. Esta crisis estructural no sólo había causado una descapitalización alarmante entre los viticultores, sino que también provocó, a la vez, la falta de perspectivas positivas que en nada beneficiaba una lucha enérgica contra la plaga.

Parece que ni siquiera el sector bodeguero en plena expansión tomó la iniciativa de una forma más contundente, quizá porque apostaba ya muy pronto por la replantación y porque podía recurrir a la importación de vinos procedentes de otras provincias, como veremos más adelante.

\subsection{Cataluña}

Cataluña fue, quizá, la región que adoptó las medidas más contundentes contra la filoxera ${ }^{16}$. El primer paso que se dio fue el intento de impedir el contagio desde el país vecino, donde la filoxera se acercaba, sin detenerse, a la frontera. La iniciativa partió del Instituto Agrícola Catalán de San Isidro, y, especialmente, del abogado y propietario viticola de Tarragona, Joan Miret, cuyo proyecto prevé́a el establecimiento de un cordón sanitario entre el Ampurdán y el Rossellón, donde viñedos franceses y catalanes se encontraban cara a cara. El proyecto de esta franja protectora significaba el descepe de una zona de $30 \mathrm{~km}$ de largo y $25 \mathrm{~km}$ de ancho y preveía la indemnización a los propietarios afectados.

La puesta en marcha de esta radical medida se encontro, no obstante, con muchas dificultades. La propuesta de una ley antifiloxérica que se basaba en el cordón sanitario, presentada ante el Gobierno en marzo de 1878, fue rechazada por el Ministerio de Fomento por estimarla inoportuna y alarmista. Dos meses más tarde esta misma medida fue aprobada en el primer Congreso Filo-

15 La Rioja, 24.10.1899.

16 La información sobre la lucha antifiloxérica en las provincias catalanas se basa en el siguiente título: IgLeSIES, J., (1968), La crisi agrária de 1879/1900: La filoxera a Catalunya. Barcelona.

Hispania, LVI/2, núm. 193 (1996) 587-622 
xérico de España, sin aclarar, sin embargo, la cuestión clave sobre quién tenía que indemnizar a los propietarios, si el estado o las diputaciones. En julio del mismo año se publicó finalmente la ley antifiloxérica, pero tampoco se llegó a una respuesta satisfactoria en este sentido.

Mientras que la franja protectora no se podía llevar a la práctica, también los trabajos antifiloxéricos, después de la aparición de los primeros focos en la provincia de Gerona, que consistran en el arranque y la quema de cepas infectadas y cercanas y en la desinfectación de la zona afectada mediante sulfuro de carbono, se encontraron con una multitud de problemas. El principal fue, sin duda alguna, la enorme hostilidad por parte de los viticultores ante estas medidas. Una actitud, por cierto, fácilmente entendible, si nos imaginamos lo que suponían para el propietario afectado: privación de los altos ingresos del comercio vinícola con Francia y destrucción de unas inversiones, que, en muchos casos, todavía no estaban amortizadas o acababan de empezar a dar beneficios.

El motín de Llers en el año 1880, en el que las brigadas antifiloxéricas resultaron agredidas por unos $\mathbf{8 0 0}$ manifestantes de diferentes pueblos, puso el punto final a los trabajos antifiloxéricos en la provincia de Gerona. A pesar de que la policía y la guardia civil, reforzadas por el regimiento de infanteria, consiguieron restablecer el orden, la lucha contra la plaga se paralizó por completo.

Unos años más tarde, cuando la filoxera amenazaba la provincia de Barcelona, se repitio el mismo episodio: intento de establecer un cordón sanitario, trabajos antifiloxéricos, un motín de los viticultores, esta vez en Maresme, y paralización absoluta de la lucha antifiloxérica.

La tercera provincia catalana afectada por la filoxera fue Tarragona, una provincia que se había beneficiado mucho de la crisis en el resto de Cataluña, lo que viene a demostrar el aumento espectacular en el cultivo de la vid antes de que fuera invadida por el insecto en el año 1888. Respecto a la lucha contra la plaga, no disponemos de muchos datos, pero, a pesar de ello, se puede afirmar que ésta, por lo menos en un primer momento, fue también bastante intensa.

La lucha contra la filoxera en Cataluña fue, sin duda, la más intensa de todo el Estado Español. Se caracterizó en muchos casos por una eficacia bastante considerable, pero también por una conflictividad destacada. Estos hechos hay que analizarlos dentro del contexto histórico de la región. En primer lugar, nos interesa la coyuntura económica del sector vitivinícola catalán cuando hizo su aparición la filoxera. Nos damos cuenta de que la filoxera invadio una región en pleno auge vitivinícola, tanto por las exportaciones a las repúblicas americanas, como por la enorme demanda procedente del país vecino, que compensaba los estragos causados por la filoxera en su propia producción vinícola mediante masivas importaciones del Estado Español. Esta coyuntura muy beneficiosa para los viticultores catalanes nos explica al mismo tiempo la alta conflictividad de los trabajos de la lucha antifiloxérica. Es muy difícil que un viticultor que vende sus productos a unos precios altamente remunerables consienta la destrucción de sus cepas mientras que alguna de ellas todavía esté en produccion; y mucho menos si consideramos que las indemnizaciones resultaban ridículas o, en algunos casos, incluso nulas. También la creencia muy 
extendida entre los viticultores modestos de que la filoxera siempre había existido, que la muerte de sus cepas la provocaba la prolongada sequía que sufra la región y que sólo había que esperar a las lluvias para que se solucionase el problema, hay que entenderla en este contexto.

Al mismo tiempo, es importante destacar que la iniciativa de la lucha antifiloxérica partía de unos sectores de la sociedad catalana que no eran en absoluto representativos. Se trataba de una élite vitivinícola, integrada en el Instituto Agrícola Catalán de San Isidro, que tenfa intereses bien distintos de los de la gran mayoria de los viticultores catalanes, mayoritariamente pequenos propietarios o arrendatarios (Rebassers). Fue sobre todo la actitud extremadamente hostil de estos últimos sectores, la que impidió una mayor eficacia en la lucha contra la filoxera.

La alta coyuntura en el sector vitivinícola en el momento de la invasion filoxérica es un hecho por lo menos en tres de las provincias catalanas, como acabamos de ver. La única excepción en este sentido fue Lérida, una provincia con poca tradición vitivinícola, que conocí́ su auge en este sector únicamente a raíz del aboom» exportador a Francia. Fue la última provincia de la region en verse afectada por la plaga a partir del año 1893, es decir, en un momento ya muy difícil para la exportación al país vecino. Desgraciadamente no disponemos de datos acerca de los intentos de lucha contra la plaga en Lérida, pero ya veremos en el capítulo sobre la replantación que el desarrollo de esta provincia se diferenciaba mucho del resto de Cataluna por encontrarse en una coyuntura vitivinícola muy mala.

\subsection{Andalucía}

Cuando el primer foco filoxérico en terreno español fue descubierto en 1878 en Moclinejo, localidad malagueña de la zona montañosa, la sorpresa fue completa, ya que se habia esperado la invasión en las zonas fronterizas con Portugal o con Francia. En seguida se constituyó la Comisión Local de Defensa contra la Filoxera, pero desde el principio sus intentos de conseguir fondos para la lucha contra la plaga sufrieron un fracaso estrepitoso. La Diputación se vio tan sólo dispuesta a ceder la ridícula cantidad de $2.500 \mathrm{pts}$. que figuraba en su presupuesto para calamidades públicas, y los capitalistas malagueños tomaron justamente esta respuesta negativa de la Diputación como pretexto para negar su propia contribución. Sin fondos, no pudo haber lucha antifiloxérica, y lo poco que se hizo, a pesar de todo, se estrelló contra la actitud hostil de los viticultores que, igual que en Cataluna, no admitian la filoxera como causa sino como efecto de sus problemas que radicaban, según ellos, en la sequra reinante ${ }^{17}$.

17 Este párrafo se basa en: Pellejero Martínez, C., (1988), «Decadencia del viñedo y crisis poblacional en la Málaga de finales del siglo XIX", Revista de Historia Económica, año VI, núm. 3, págs. 593-633.

Hispania, LVI2, núm. 193 (1996) 587-622 
La respuesta bastante lánguida e ineficaz contra la filoxera en Málaga contrasta mucho con el dinamismo descrito en el capítulo sobre Cataluña. De ahí también la imagen de una burguesía malaguefia poco emprendedora frente a unos capitalistas catalanes modélicos; lo que provocó una pequeña polémica entre historiadores de las dos regiones. Pero el debate es sano y ha llevado a una visión mucho más profunda del tema.

La buguesía malagueña, por varias razones, no tenía por qué tomar un papel activo en la lucha antifiloxérica. En primer lugar hay que analizar el momento coyuntural del sector vitivinícola malagueño en el año 1878. Sus dos ramos principales, el de la pasa y el del vino, dos sectores bien separados con una dinámica económica propia, tenían en los años de la invasión filoxérica algo en común: la profunda crisis en la que se encontraban los dos.

El sector pasero malaguefio venía luchando ya desde hace años con enormes dificultades en los mercados internacionales, especialmente en el principal, Estados Unidos, a causa de la competencia, tanto de la pasa californiana, como de la turca y de la griega. Una crisis de sobreproducción acompañada por una depreciación tangible de la pasa fueron las consecuencias de esta evolución ${ }^{18}$. No extraña, por lo tanto, que la burguesía vitícola malagueña de la Hoya y del Litoral implicada en este ramo de la viticultura, en un primer momento se cruzara los brazos y no emprendiera nada en contra de la plaga. Además, como el insecto afectó primero a la zona montañosa, muchos viticultores y capitalistas de la Hoya lo verían con buenos ojos, puesto que de esta manera les libraba de una competencia muy molesta. Esta actitud idiferente desapareció, sin embargo, en el momento en que se vieron afectados ellos mismos por la plaga, como veremos más tarde.

No solo el sector de la pasa sino también el sector vinícola malagueño se encontraba en aquellos años en una crisis, que habla tenido su origen ya en los años 1850/60 y que había sido causada por varios factores entre los que destacan el cambio de gusto en el mercado inglés y el aumento de la escala alcohblica en las tarifas aduaneras inglesas ${ }^{18}$. Aunque a partir de 1873 las exportaciones de vino desde el puerto de Málaga empezaron a recuperarse, la crisis no se solucionó porque en muchas de estas partidas exportadas se trataba de vino de las provincias del interior, destinado a abastecer el mercado francés.

El sector vinícola malagueño tradicional ligado muy estrechamente al vino seco y de alta graduación alcohólica de marca Málaga, al intentar restablecer la calidad y la fama de los tiempos pasados, mejoró algo su posición, pero sin Ilegar, ni mucho menos, a los niveles de exportación anterior.

Se trata, por consiguiente, no tanto de una cuestión de capacidad de respuesta frente a la filoxera por parte de la burguesía malagueña, sino de un cálculo minucioso y de una evaluación realista respecto a la coyuntura económica que justificaban o no las medidas costosas de la lucha antifiloxérica. El sector

18 lbid., págs. 614 y ss.

19 lbid, págs. 605 y ss.

Hispania, LVI/2, múm. 193 (1996) 587-622 
uvero almeriense es la mejor prueba de esta afirmación, como veremos más en adelante cuando tratemos de la repoblación.

\section{LA REPLANTACION}

La única solución eficaz para hacer frente a la filoxera fue -y lo es aún hoy- la replantación del viñedo con variedades de vid americana, fuera injertando variedades europeas sobre pies americanos of fuera utilizando productores directos. Las experiencias en Francia lo habían demostrado de sobra y es improbable que en España no se haya tenido esta misma opinion. Otra cosa muy distinta es el momento en que se dejan las medidas defensivas contra la filoxera para dar el paso hacia la replantación.

\section{II.1. Cataluña}

En Catalufia la lucha antifiloxérica se basaba al principio, como hemos visto, en acciones defensivas con el fin de mantener la vida de las cepas atacadas el mayor tiempo posible y de frenar la propagación de la plaga, hechos que solo tienen su explicación en la coyuntura favorable en la que se encontraba la viticultura catalana.

Una vez destruida la mayor parte del vifiedo de las provincias catalanas y careciendo las medidas meramente defensivas de sentido, se empezó con la replantación de los viñedos. La intensidad de la replantación variaba sustancialmente de provincia a provincia, y su resultado presenta diferencias muy importantes, como se podrá deducir de la siguiente tabla ${ }^{20}$ :

Areas máximas
$1879-1889$
$39.924 \mathrm{ha}$
$132.755 \mathrm{ha}$
$111.152 \mathrm{ha}$
$119.741 \mathrm{ha}$

$$
\begin{gathered}
\text { Areas en } \\
1931-35
\end{gathered}
$$

$\begin{array}{lr}\text { Gerona } & 39.924 \mathrm{ha} \\ \text { Barcelona } & 132.755 \mathrm{ha} \\ \text { Tarragona } & 111.152 \mathrm{ha} \\ \text { Lérida } & 119.741 \mathrm{ha}\end{array}$

$\begin{array}{rr}13.901 \mathrm{ha} & 34,8 \% \\ 118.807 \mathrm{ha} & 89,5 \% \\ 91.604 \mathrm{ha} & 82,4 \% \\ 29.087 \mathrm{ha} & 24,3 \%\end{array}$

Comparando, por ejemplo, el área replantada de la provincia de Barcelona (valor máximo) con la de Lérida (valor mínimo) nos damos cuenta de que la enorme diferencia no puede basarse únicamente en el éxito o fracaso de los esfuerzos replantadores en cada provincia. Mucho más importante será analizar los incentivos o las necesidades para replantar los viñedos, y, de

20 PUjol ANDreU, J., (1986), «La crisis de sobreproducción en el sector vitivinícola catalán, 1892-1935", en: Garrabou, R./BARCTELA, C./JIMENEZ BlanCo, J., (eds.), Historia agraria de la España contemporánea, t. 3: El fin de la agricultura tradicional (1900-1960), Barcelona: Crítica, pág. 331.

Hispania, LVI/2, nứm 193 (1996) 587-622 
hecho, nos encontramos en los dos casos ante circunstancias bien distintas. En la provincia de Barcelona la filoxera apareció unos 13 años antes que en Lérida. Los primeros intentos de replantación se llevaron a cabo en pleno «boom» exportador y todavía después del año 1892 el vino de esta provincia se vendió a precios, aunque más bajos, todavia remunerativos. La demanda francesa no fue el único condicionante para la viticultura barcelonesa, porque, de hecho, los mercados americanos y, más tarde, el mercado interior español tuvieron un peso bastante importante en la producción vinícola de esta provincia.

En la provincia de Lérida la dependencia directa y única del mercado francés fue muchísimo más acentuada. Mientras que en Barcelona y Tarragona la superficie dedicada a viñedo creció hasta mediados de los años 1880 un 15,3 y un 14,5 por 100 respectivamente, en Lérida esta expansión llegó a un 90 por $100^{21}$. El hecho de contar con un mercado más o menos diversificado y de tratarse de una zona vitícola tradicional o meramente coyuntural jug6, por lo tanto, un papel importantísimo en la superación de la crisis filoxérica y en la replantación.

Pero no se trata sólamente de una cuestión de incentivos económicos. También el grado de capitalización o descapitalización de una región representaba un factor decisivo a la hora de replantar. Si la crisis filoxérica coincidió con una coyuntura favorable para el sector vitivinícola de una provincia también existían más fondos para afrontar los altos gastos de la repoblación. Si coincidió con una crisis ya existente la descapitalización anterior impidió tales esfuerzos economicos.

Por lo tanto, el éxito de la replantación dependía en un grado muy alto de las perspectivas y de los intereses económicos individuales y colectivos, sin olvidar otros factores como la productividad de las nuevas plantaciones que por los gastos más elevados de cultivo tenían que superar la de los vinedos anteriores y, por ello, sólo podía alcanzarse en los mejores terrenos vitícolas. Otros factores importantes son el grado de organización entre los viticultores para afrontar los problemas técnicos y económicos de la replantación, el apoyo de la administración (por ejemplo, en el campo de los créditos o subvenciones), el grado de compromiso de los terratenientes en la replantación llevada a cabo por sus arrendatarios y la distribución de la propiedad en general. Finalmente, inflúa también la aptitud de los terrenos, o las posibilidades de adaptarlos, para cultivos alternativos con alto valor en los mercados, como lo fue, por ejemplo, el caso de la naranja en Valencia ${ }^{22}$.

21 Ibid., pág. 320.

22 PALAFOX GAMIR, J., (1987), «Exportaciones, demanda interna y crecimiento económico en el País Valencianom, en: SANCHEZ ALBORNOZ, N., (ed.), La modemización económica de España 1830. 1930, Madrid: Alianza, págs. 319-343. PıQUeRAs, J., (1985), La agricultura valenciana de exportación y su formación histórica, Madrid: Serie Estudios Agrarios, Pesqueros y Alimentarios. CALATAYUd, S., (1989), Capitalismo agrario y propiedad campesina, La Ribera de Xüquer (Valen. cia) 1860-1930, Valencia.

Hispania, LVI2, núm. 193 (1996) 587-622 


\section{II.2. Andalucía}

Comparado con Cataluña, el éxito de la replantación de los viñedos andaluces fue mucho más modesto, como lo demuestra la siguiente tabla ${ }^{23}$ :

$$
\begin{gathered}
\text { Superficie } \\
1878
\end{gathered}
$$

Almería
Granada
Jaén
Málaga

$$
\begin{array}{r}
11.000 \mathrm{ha} \\
35.814 \mathrm{ha} \\
9.588 \mathrm{ha} \\
112.872 \mathrm{ha}
\end{array}
$$

\section{Superficie 1909}

$\begin{array}{rrr}5.475 \mathrm{ha} & 49,77 \\ 9.510 \mathrm{ha} & 26,55 \\ 3.447 \mathrm{ha} & 35,95 \\ 24.180 \mathrm{ha} & 21,42\end{array}$

Esta visión global de la parte oriental de la región andaluza nos da, pues, una imagen de una replantación bastante mediocre e induce a calificarla como fracaso. Si hablamos de fracaso del esfuerzo replantador, partimos, sin embargo, de la voluntad generalizada de querer emprender esta renovación en las provincias andaluzas; hecho muy cuestionable si analizamos esta evolución algo más detalladamente.

Tanto como la lucha antifiloxérica, el hecho de replantar o no dependía en muy alto grado de las perspectivas económicas del sector y de los diferentes subsectores vitivinícolas, es decir, de la coyuntura económica en la que se hallaban los sectores vinícola, pasero y uvero de la región. La disponibilidad de fondos para afrontar los altos costes de la renovación del viñedo, a su vez, jugaban un papel decisivo.

En el caso de la provincia malagueña llama la atención que en el tema de la repoblación existió una diferencia considerable entre la zona montañosa, por un lado, y la Hoya malagueña y el Litoral, por otro. Mientras que los viticultores paseros de la Axarquía, en su gran mayoria pequeños propietarios, no disponian ni de los fondos, ni de los incentivos económicos para repoblar, la situación en la Hoya y en el Litoral se presentaba muy diferente. En primer lugar, se trataba en muchos casos de propietarios económicamente más fuertes con tíerras de mejor calidad; lo que les permitió no sólo replantar, sino aumentar, al mismo tiempo, su competitividad en los mercados mediante la mejoria de sus cultivos de uva pasera para alcanzar una productividad muy superior a la anterior a la plaga. Disponían, además, de un incentivo económico muy importante, el hundimiento de la competencia de la zona montañosa, que les colocó en una situación bastante ventajosa para futuras exportaciones de pasas.

23 Morilla Crutz, J., (1988), «Las condiciones de comercialización de los productos vitícolas y respuesta a la filoxera en Andalucía Oriental (1873-1914)», Revista de Historia Económica, núm. 3 , pág. 572 .

Hispania, LV1/2, núm. 193 (1996) 587-622 
El éxito de la replantación en alguna zona de la Hoya y del Litoral y el fracaso estrepitoso de los esfuerzos de la zona montañosa también tenían sus raíces en un importante hecho biológico. Los primeros intentos de repoblación con cepa americana en la provincia de Málaga se efectuaron utilizando el patrón americano de Riparia, que dio muy buenos resultados en tierras llanas y fracas 6 plenamente en zonas montañosas, donde habia que sustituirlos por la variedad de Rupestris Lot. Las zonas de la Hoya y del Litoral malagueño contaron, por lo tanto, con una doble ventaja que puede explicar su mayor éxito ${ }^{24}$.

Dejando ya el sector pasero malagueño y centrándonos en la la vitivinicultura en general de Andalucía Oriental, hemos de tener en cuenta, ante todo, la complejidad de este sector. No se trata, como en Cataluña o en La Rioja, de un sector más o menos homogéneo con un único producto comercializado como el vino común, sino de un sector con tres subsectores bien diferenciados; es decir, el del vino, el de la pasa y el de la uva fresca. Cada uno de estos tres sectores podía estar influido por coyunturas muy diferentes y, en cuanto a la replantación, más o menos favorecido. Por ello, es importante comparar la distribución del sector vitícola en estos tres subsectores antes y después de la plaga ${ }^{25}$.

Distribución en subsectores de la vitivinicultura de Andalucía Oriental (Almería, Málaga, Granada, Jaén):

1878

$\begin{array}{lcc}\text { Vino } & 70,2 \% & 24,5 \% \\ \text { Pasa } & 26,4 \% & 28,5 \% \\ \text { Uva fresca } & 3,4 \% & 47,0 \%\end{array}$

Estos datos son muy significativos. Demuestran una expansión sin precedentes de la comercialización de la uva fresca, que en plena crisis filoxérica vivia su época más dorada. A la cabeza de este subsector se encotraba, sin duda alguna, la provincia de Almería que fue, de hecho, la primera provincia andaluza en relación con la replantación. Pero también los viticultores uveros de Málaga se distinguieron por una decidida acción contra la filoxera ${ }^{26}$. El sector uvero contaba, además, con otra ventaja importante. El hecho de ser el último sector que se vio afectado por la plaga filoxérica le proporcionó la posibilidad de basar sus esfuerzos replantadores en las muchas experiencias, tanto de fracaso como de éxito, de las zonas de pasa y de vino antes afectadas.

24 Pellejero Martinez, C., (1986), «La crisis agraria a finales del siglo xix en Málaga, Revista de Historia Económica, núm. 3, pág. 572.

2s La siguiente tabla se encuentra en: Morilla Critz (1988), op. cit., pág. 58.

26 Morilla CrITZ, J., (1989), Cambio en la citicultura de Andalucía Oriental durante la crisis de finales del siglo XIX. Estudio sobre los datos de los informes consulares británicos», Revista de Historia Económica, núm. 1, pág. 166.

Hispania, LVI2, nim. 193 (1996) 587-622 
Fijémonos, por último, en la zona de Jerez ${ }^{27}$. Esta región, cien por cien vinatera, estaba pasando, como lo vimos también en el caso de Málaga, momentos difíciles, por los problemas que sufrían sus vinos en los mercados tradicionales, sobre todo en el inglés. Lo más destacado en cuanto a la replantación en esta región lo resume muy bien la siguiente cita del Cónsul inglés en el año 1902:

«Solamente los propietarios de vinos más ricos han podido volver a plantar sus viñas y esperar a mejores tiempos. [...] Muchas otras propiedades podrian trabajarse de la misma manera si es que una mayor demanda de Jerez justificara el gasto.» ${ }^{28}$

Esta tendencia nos la documentan dos estudios con cifras. En un artículo de Zoido Naranjo se nos demuestra que en 1909 sólo un 30\% de la Campina de Jerez se encontró replantada, y que la mitad de estas viñas pertenecía a sólo 29 propietarios, la mayoría de ellos exportadores ${ }^{29}$.

Cabral llega a resultados algo diferentes que confirman, sin embargo, esta misma tendencia. Según él, 40 casas exportadoras eran propietarias de 1000 ha de las 2.500 hectáreas replantadas en Jerez ${ }^{30}$.

Esta concentración de la propiedad vitícola después de la plaga no es, como veremos más tarde, responsabilidad única de la plaga, sino que refleja unos cambios estrucurales en la vitivinicultura jerezana iniciados mucho antes. Al insecto destructor le corresponde, no obstante, el papel de darle a esta evolución un carácter definitivo.

\section{II.3. Provincia de Logroño}

La replantación del viñedo riojano pasó por tres fases fácilmente distinguibles. La primera se caracterizó por algunos modestos intentos tanto por parte de la administración riojana como de particulares en un ambiente generalizado de extrema hostilidad hacia la replantación. La segunda es la replantación realizada por los propietarios económicamente bien situados, acompañada de alguna iniciativa colectiva. La tercera y definitiva será la repoblación impulsada por la Diputación Provincial que dio vida a una Caja Vitícola, que hizo posible que los viticultores más modestos fueran capaces de replantar sus viñedos, ofreciéndoles plantas americanas a crédito con intereses muy moderados.

27 Zoido Naranjo, F., (1980), «Observaciones sobre la crisis filoxérica y sus repercusiones en la vitivinicultura de Jerez?, Archivo Hispalense, núm. 193/94, págs. 487-507. SIMPSON, J., (1985), «La producción de vinos en Jerez de la Frontera 1850-1900», en: MARTiN ACENA, P.PRADOS DE LA Escosura, L., (eds.), La nueva historia económica en España, Madrid: Tecnos.

28 SIMPSON (1985), op. cit., pág. 186.

29 Zollo (1980), op. cit., pág. 501/2.

30 Cabral Chamorro, A., (1987), «Observaciones sobre la regulación y ordenación del mercado del vino en Jerez de la Frontera 1850-1935; los antecedentes del consejo regulador de la denominación de origen Jerez-Xérès-Sherry», Agricultura y Sociedad, núm. 44, julio/sept., pág. 191. 
En 1899, año en que La Rioja fue alcanzada por la plaga, el diario La Rioja ya publicó algún artículo en favor de la replantación con cepas americanas ${ }^{31}$. Poco después, el Real Decreto del 29.1.de 1900 declaró la provincia invadida por la filoxera poniendo asf la base de una eventual replantación. También la Diputación se mostró muy decidida para empezarla cuanto antes, autorizando la introducción de plantas americanas para crear viveros en las zonas afectadas.

La opinión pública no siguió, sin embargo, esta corriente. Al contrario, a iniciativa del municipio de Haro se llegó a organizar una campaña en contra de la replantación que tuvo el apoyo de numerosos pueblos, pidiendo, como primera medida, la inmediata revocación de la susodicha. Real Orden hasta que no estuvieran invadidas por lo menos las dos terceras partes de la provincia ${ }^{32}$.

Entre 1901 y 1903 la confrontación entre propietarios dispuestos a replantar y la mayoría de los pequeños viticultores que se lo querían impedir alcanzó su intensidad más fuerte. Manifestaciones multitudinarias, amenazas y, con cierta frecuencia, arranques y desmoches de viñas con cepas americanas, obligaron a muchos de los ricos propietarios dispuestos a replantar a retardar su proposito o a intentarlo en otro municipio ${ }^{33}$.

Si analizamos esta actitud hostil ante la repoblación mostrada por la gran mayoria de los viticultores riojanos llegamos a dos explicaciones ${ }^{34}$ : Por un lado, se trata de un miedo fácilmente comprensible ante una introducción o propagación de la plaga como consecuencia de plantación de cepas americanas. Este rechazo, que podríamos llamar «rechazo temporal», tendía a disminuirse con la propagación de la plaga. Es decir, cuantos más pueblos se vieron afectados por la filoxera en un grado importante, menos resistencia se opuso contra la replantación. Esta explicación es plenamente válida respecto a la actitud tomada por los grandes propietarios que, oponiéndose en un primer momento a la replantación, fueron los primeros en aceptarla.

La segunda explicación va más al fondo y refleja un conflicto de clase subyacente. Se trata del rechazo de los pequeños viticultores y, en muchos casos, de los jornaleros del campo, que se opusieron abiertamente contra una solución que no estaba al alcance de sus posibilidades. La replantación del vifiedo mediante injertos sobre pie americano fue un remedio extremadamente costoso, ya no sólo por el precio de las plantas, sino también por las técnicas de plantación que requerian unas inversiones importantes que la mayoría de los viticultores riojanos no estaban en condiciones de afrontar. La oferta de Guillermo Varela, un viticultor de Orense que apareció en La Rioja ofreciendo un

31 La Rioja, 17.08.1899 y 5.10.1899.

32 La Rioja, 26.05.1900.

33 OESTREiCHER, A., (1992), Die Reblausplage in der spanischen Region La Rioja. Soziàl-und wirsschaftsgeschichtliche Untersuchung des Weinsektors der spanischen Region La Rioja zwischen 1860 und 1915. Zürich (Memoria de licenciatura inédita), pág. 53.

${ }^{34}$ Ibid., págs. 54-56.

Hispania, LVI/2, núm. 193 (1996) 587.622 
remedio milagroso y barato contra la filoxera, y la sorprendente movilizacion entre los viticultores riojanos en su favor demuestran muy bien esta componente del conflicto ${ }^{35}$.

Después de 1903 la oposición contra la repoblación fue desapareciendo y se abrió un periodo en el que los propietarios ricos, y entre ellos muchas de las bodegas industriales, se dedicaron a la replantación. Paralelamente, se establecieron en la provincia varias casas de viveristas que empezaron a comercializar a gran escala las plantas americanas. Entre ellas también se hallaban algunas bodegas, como, por ejemplo, las Franco-Españolas que tenían representación en 16 municipios de la provincia ${ }^{36}$. En general, podemos decir que el lema de los años hasta 1910 fue el de "cada uno por su cuenta", aunque sí existieran algunos esfuerzos colectivos $u$ organizados para hacer frente a la replantación.

En este sentido, es interesante una iniciativa que partió del abogado y propietario vitícola Ricaredo Saenz de Santa María de Haro, típico representante de la burguesía vitícola riojana, que fundó la «Junta de Fomento de Intereses Locales» con el fin primordial la recuperacion económica de la ciudad ${ }^{37}$. Mediante una suscripción pública intentó juntar fondos para la adquisición de material técnico y orgánico para la replantación, entendiendo que la situación precaria que atravesaba el municipio radicaba en el estado desesperante de la viticultura. El resultado de esta iniciativa es muy esclarecedor, puesto que casi todas las bodegas industriales de esta ciudad aportaron cantidades importantes, manifestando así su clara voluntad y sus intereses tangibles en la recuperación de los viñedos harenses. Las 33.000 pts. conseguidas por la suscripción se invirtieron, más que en una ayuda directa a los pequeños viticultores, en forma del reparto de plantas americanas, como en un primer momento se planté, en la adquisición de unos trenes de desfonde, en el establecimiento de una escuela de injertores y en otras actividades como, por ejemplo, la organización de una feria de maquinaria agrícola. Es decir, una vez más predominaron los intereses de los grandes, puesto que tanto la escuela de injertadores como la adquisición de una maquinaria que servía sobre todo para su empleo en fincas de cierto tamaño tenfan poco sentido para un viticultor modesto.

Existían, sin embargo, bodegas cuyos intereses estaban estrechamente ligados a los viticultores circundantes que les abastecian de la materia prima. En estos casos las bodegas sí apoyaron de manera directa los esfuerzos de replantación de los viticultores. Un ejemplo es la bodega del Marqués de Riscal que estableció un vivero de cepas americanas en el año 1902 para la replantación de sus propias fincas y que vendía a sus proveedores tradicionales estas plantas a precios de coste ${ }^{38}$.

3S Oestreicher, A., «Algunos aspectos de la historia del sector vitivinícola riojano, 1860$1915 n$; en: Berceo.

36 La Rioja, 23.04.1913.

37 Desarrollado en OESTREICHER (1992), op. cit., págs. 62 y ss.

38 La Rioja, 20.07.1902. 
En general, sorprende, no obstante, la poca iniciativa en estos primeros años tanto de los fuertes capitalistas como de la administración controlada por ellos, cuando se trataba de apoyar en una mayor escala a los pequeños viticultores que sin esta ayuda se veían sin los medios de tirar hacia adelante. Mediante las siguientes hipótesis será quizá más fácil entender el porqué de esta actitud poco colaboradora:

- La Rioja venía sufriendo desde 1892 las consecuencias de una sobreproducción extremadamente grave cuyas raíces estaban en el desproporcionado aumento del cultivo de la vid durante los años del «boom» exportador. Por ello, la élite vitivinícola riojana, en un primer momento, no tuvo ningún interés en apoyar la replantación a gran escala.

- El sector bodeguero riojano estaba en condiciones de abastecerse de su materia prima desde fuera de la provincia, importando vino de Cataluña, La Mancha o Valencia, como veremos más tarde.

- Los pequeños viticultores riojanos no disponían de una fuerte organización propia capaz de presionar a la Diputación para que apoyase materialmente el proceso de replantación en sus parcelas. Las organizaciones agrarias que existian estaban plenamente controladas por grandes propietarios o capitalistas.

En el ano 1910 cambió finalmente esta actitud del «laisser-faire» por parte de la administración y dio lugar a una política mucho más emprendedora en el tema de la replantación. La creación de una Caja Vitícola Provincial, impulsada por el presidente de la Diputacion, el independiente Francisco Martínez Zaporta, fue el inicio de una campaña intensa por parte de esta institución ${ }^{39}$.

La Caja Vitícola se parecía bastante a los bancos agrarios existentes entonces en la Península, con intereses bajos y una estrecha relación con la agricultura, sólo que en este caso sirvió particularmente para el sector vitícola y, en concreto, para la replantación de viñedos. La Diputación aumentó de manera espectacular la producción de estacas americanas en sus propios viveros, adquirio algunos trenes de desfonde y lo puso todo, en forma de crédito, a disposición de los viticultores. Estos disfrutaban de un plazo de cinco años antes de tener que pensar en la devolución del préstamo, con un interés módico de un $5 \%$ anual. Los fondos necesarios para afrontar estos gastos provenían de una emisión de letras de participación con un interés del $5 \%$, que se ofreció a los capitalistas riojanos.

Pero, ¿qué hizo exactamente cambiar de política a la administración y por qué no antes? La explicación oficial fue que los fondos privados se habían agotado por los esfuerzos de la replantación y que, por ello, sería necesario un

\footnotetext{
39 Ampliamente desarrollado en OEsTREłCHER (1992), op. cit., pág. 74 y ss.

Hispania, LVI/2, núm. '193 (1996) 587-622
} 
nuevo impulso. Pero existían también, sin duda alguna, otros factores, menos oficiales, que llevaron a este giro. La crisis generalizada en la región junto con los primeros indicios de falta de mano de obra por la constante emigración entre 1900 y 1910 significaban una situación insostenible para la provincia. Sobre todo si tenemos en cuenta que en La Rioja la mayoría de la oferta de mano de obra provenía de los pequeños propietarios que para sobrevivir ejercran trabajo asalariado.

Otra hipótesis, que desgraciadamente no podemos demostrar a través de las fuentes, sería la de interpretar la Caja como respuesta del sector liberal a los cada vez más numerosos sindicatos agrícolas católicos, afines al sector conservador, que en 1909 se habían constituido en federación y que tenían un éxito enorme entre la población rural y especialmente entre los pequeños viticultores.

Sea como sea, la replantación del viñedo riojano recibió tanto por la Caja Vitícola como por los Sindicatos Católicos un fuerte impulso a partir de 1910; de esta manera, se posibilitó también a viticultores más modestos conseguir los fondos necesarios. Aun así, si comparamos el viñedo repuesto con el vin̄edo prefiloxérico, llama la atención la drástica redimensión del sector ${ }^{40}$.

$\begin{array}{lccc}\text { Comarca } & 1902 & 1922 & \% \\ \text { Alfaro } & 3.190 \mathrm{ha} & 1.800 \mathrm{ha} & 56,4 \\ \text { Calahorra } & 3.220 \mathrm{ha} & 1.900 \mathrm{ha} & 59,0 \\ \text { Cervera } & 1.700 \mathrm{ha} & 1.155 \mathrm{ha} & 67,9 \\ \text { Arnedo } & 4.400 \mathrm{ha} & 2.200 \mathrm{ha} & 50,0 \\ \text { Logroño } & 10.500 \mathrm{ha} & 6.000 \mathrm{ha} & 57,1 \\ \text { Nájera } & 9.802 \mathrm{ha} & 3.500 \mathrm{ha} & 35,7 \\ \text { Haro } & 17.330 \mathrm{ha} & 6.500 \mathrm{ha} & 37,5 \\ \text { Sto.Domingo } & 2.450 \mathrm{ha} & 500 \mathrm{ha} & 20,4 \\ \text { Total } & 52.592 \mathrm{ha} & 23.555 \mathrm{ha} & 44,8\end{array}$

La comarca de Haro fue una de las más castigadas por no disponer de alternativas productivas como, por ejemplo, la Rioja Baja, que disponía de más tierras de regadío y donde existía una potente industria conservera. Por ello, el éxodo de emigrantes riojanos afectó sobre todo a los pueblos de Haro, es decir, justamente a los que durante los años 70 y 80 más habían crecido y expandido su producción vitícola.

\section{EL IMPACTO SOCIAL DE LA FILOXERA}

La crisis filoxérica arrastró siempre, fuera donde fuera, un alto potencial de conflictividad social, a veces agudizando conflictos anteriores ya existentes $y$, a veces, pero en menor medida, creando nuevos.

40 Datos sacados de Provedo (1987), op. cit., págs. 158/199.

Hispania, LVI/2, núm. 193 (1996) 587-622 


\section{III.1. Cataluña}

En el caso de Cataluña la conflictividad social estalló alrededor de un proceso que conocemos hoy como "cuestión rabassaire" y cuyas raíces datan de fechas muy anteriores a la filoxera ${ }^{41}$. Se trata de un contrato de arrendamiento que empieza con la plantación de una viña por un agricultor y cuya duración está determinada por la muerte de dos tercios de esta viña. En caso de suceder eso, la finca volvía a ser propiedad única del terrateniente. Mientras duraba el contrato, el viticultor se comprometía, a su vez, a cederle al propietario una parte, en la mayoría de los casos un tercio, de su cosecha. Mediante las técnicas del renuevo de las viñas los rabassers habían consegutido darle a la viña una vida ilimitada, con lo que se aseguraron su dominio útil por un tiempo indefinido.

Ya en la primera mitad del siglo XIX los propietarios intentaron, con mayor o menor éxito, desnaturalizar este contrato que les privaba del derecho de desahucio. Querían limitar su duración a $\mathbf{5 0}$ años al cabo de los cuales o había que renovar el contrato o la tierra volvía a plena disposición de su dueño.

Lo que los terratenientes no habían conseguido durante décadas, con la invasión filoxérica parecía de repente al alcance de sus manos, ya que las cepas estaban muertas, y habia que empezar otra vez desde cero. Según ellos, el contrato de "rabassa morta" terminó con la muerte de las cepas afectadas por la plaga, mientras que los viticultores, organizados en la Unió de Rabassaires, pedían la renovación de los contratos y, por los gastos que suponía la replantación, mejores condiciones contractuales. La filoxera hizo, por lo tanto, estallar el conflicto con una violencia desconocida hasta entonces, tanto contra bienes como contra personas.

S6́lo hacia 1896 esta agitación empez 6 a disminuir, cuando la necesidad de la replantación forzó a que se avecinasen las posturas, llegándose a acuerdos que a primera vista favorecían a los labradores, ya que en la mayoría de los casos contenían mejoras contractuales importantes. Pero sólo a primera vista, pues los nuevos contratos, que habían perdido su condición de rabassa morta, fueron en muchos casos sólo verbales y habłan devuelto al propietario el dominio ilimitado de sus tierras.

Después de la filoxera los contratos a rabassa morta ya no representaban ni un $10 \%$ del total de los contratos de cultivo $y$, de esta pequeña parte, ninguno tenía ya una duración indefinida.

41 Balcells, A., (1980), El problema agrario en Cataluña. La cuestión Rabassaire (18901936), Madrid. BalCELls, A., (1977), «La conflictividad social azgraria en Cataluña y la Unió de Rabassaires hasta 1939», Agricultura y Sociedad, núm. 2. Ferrer I ALÓs, L., (1991), «La pequeña explotación en un viñedo de la Catalứa Central en los siglos XIX y XX. Consideración sobre su evolución y comportamiento", en: SAAVEDRA, P./VLLARES R., (eds.), Señores y campesinos en la península ibérica, siglos XVII-XX, t. 2, Campesinado y pequeña explotación, Barcelona, págs. 34-62.

Hispanio, LVI/2, nưm. 193 (1996) 587-622 


\section{III.2. Andalucía}

La región andaluza es quizá el prototipo de una región con una fuerte conflictividad social de carácter rural, debido fundamentalmente a su estructura latifundista. No es aquí el lugar de intentar una síntesis de la amplia bibliografía existente, ni de tocar el tema del anarquismo rural andaluz.

Por estas razones nos limitamos a describir muy brevemente la situación en Málaga durante la plaga filoxérica. Salta a la vista la grave crisis poblacional por la que pasó a finales del siglo XIX y especialmente durante la década de 1887 a 1897, es decir, durante el periodo en el que más duro fue el impacto de la filoxera.

Sería, sin embargo, un error responsabilizar únicamente a la crisis filoxérica del éxodo de malagueños en aquellos años. Influían más factores en ello; es decir, se trataba de una crisis económica que sobrepasaba por mucho el sector vitivinícola, ya que coincidía también con una situación difícil de la industria y del comercio malagueños. Lo que sí resulta evidente es que la filoxera agravó de manera brutal la difícil situación económica ya existente. Tanto la crisis de la industria textil y siderúrgica malagueña, como las dificultades en el mercado exterior vinícola y pasero, impedían que la pérdida de los viñedos fuera compensada por alguna coyuntura favorable en otros sectores.

Comparando las tendencias emigratorias de las diferentes comarcas de la provincia, vemos que la Axarquía fue la más afectada desde el punto de vista poblacional ${ }^{42}$. La gran importancia del cultivo de la vid y el carácter minifundista de los propietarios no dej6 a muchos viticultores otra alternativa que la emigración, al principio a la capital en busca de un empleo y en muchos casos también hacia otras provincias o al extranjero. Se trata en este caso del "golpe de gracia" que la filoxera dio a una comarca que ya se habia encontrado en una situación muy difícil y por ello no podía emprender pasos decisivos para salir de ella.

\section{MI.3. Provincia de Logroño}

También en La Rioja nos encontramos con una grave crisis demográfica ${ }^{43}$, sobre todo en la primera década del siglo xx, periodo en que la filoxera acabó definitivamente con los viñedos riojanos. Este éxodo riojano fue precedido, sin embargo, por otro fenómeno social: los conflictos obreros que a partir del 1902 empezaron a reflejarse en los periódicos ${ }^{44}$.

42 Pellejero (1988), op. cit. pág. 623.

43 Entre 1900 y 1910 emigraron 20.963 personas de La Rioja; GaLlEGo MARTiNEZ, D., (1986), La producción agraria de Álava, Navarra y La Rioja, (tesis doctoral), Madrid, pág. 925.

44 Más detallado en OesTREICHer (1992), op. cit., págs. 120 y ss. 
La situación en el sector vitivinícola había empezado a empeorar ya a partir de 1892, cuando el gobierno Francés cerró sus fronteras al vino español mediante la subida de las tarifas aduaneras. Las primeras movilizaciones de los obreros agrícolas riojanos las presenciamos en relación con las protestas contra la vid americana y la replantación; algo logico, si tenemos en cuenta que el mayor argumento contra la introducción de estas plantas fue el peligro de que propagaria la plaga en los viñedos riojanos. A partir de 1902 se nota, no obstante, otra preocupación de la clase obrera que empez 6 a movilizarse para conseguir sueldos más altos y contratos de trabajo más seguros.

Entre 1902 y 1904 se reflejan 18 huelgas de obreros agricolas en los medios de comunicación regionales, la gran mayoría de ellas en la Rioja Alta, y con las siguientes peticiones: aumentos de sueldo, prohibición de la contratación de jornaleros de otras regiones y fijacion de contratos laborales para todo el año. El aumento de las movilizaciones obreras justo en estos momentos no es ninguna casualidad. Fueron los primeros años en los que se empezaron a notar los efectos de la crisis filoxérica y el inicio del endurecimiento de la situación laboral para los jornaleros que ya antes se habían encontrado en una situación muy precaria, por no decir límite. Los conflictos laborales hay que interpretarlos como estrategia de supervivencia, antes de resignarse en lo que para muchos iba a ser la única salida: la emigración. Así se explica también que a partir de 1905 las noticias sobre huelgas y otras formas de movilización obrera desaparecieran repentinamente $y$, al mismo tiempo, aumentaran de modo espectacular los testimonios sobre la emigración de numerosas personas riojanas. $\mathrm{Ni}$ la beneficiencia que experimentó un auge importante en aquellos años, ni los programas de trabajo público para parados (limpieza de calles, obras públicas etc.), impulsados por los ayuntamientos para mantener el orden público, fueron capaces de evitar este último recurso para muchos riojanos y riojanas.

Parece que la crisis, que en 1905 habia alcanzado unos niveles tan catastróficos por la perdida de una gran parte de los viñedos riojanos, debilitó ella misma la resistencia de la clase obrera agrícola, que para sobrevivir tuvo que pensar en otra salida. Esta hipótesis se confirma si tenemos en cuenta que a partir de 1912, cuando se empezó a notar una ligera mejora en el campo riojano, las manifestaciones y huelgas de los obreros de campo reaparecieron y llenaron otra vez los periódicos locales.

No todas las comarcas riojanas se vieron igualmente afectadas por la crisis. La capital y algunos municipios de la Rioja Baja crecieron entre 1900 y 1910 , o, por lo menos, no perdieron tanta población como la Rioja Alta, la comarca más afectada ${ }^{45}$. Ya nos hemos referido a la agricultura mucho más diversificada en la Rioja Baja por el hecho de existir una industria conservera importante y un porcentaje más alto de tierras de regadío. Por lo que respecta

45 Evolución demográfica por municipios riojanos en OESTREICHER (1992), op. cit., págs. $\mathrm{I} 28 / 29$.

Hispania, LVI/2, núm. 193 (1996) 587-622 
a la capital riojana, ofrecía como ciudad más importante de la región más posibilidades de trabajo que la Rioja Alta que dependía casi exclusivamente del sector vitivinicola. Constatamos, por ello, al lado de una emigración hacia otras provincias y hacia el extranjero, un importante flujo migratorio dentro de la misma provincia.

A partir de 1910, después de diez años de emigración, y al recuperarse muy lentamente la víticultura riojana, los periódicos empiezan a darnos cuenta de una tendencia totalmente inversa, es decir, la de la falta de brazos en épocas muy determinadas del año y la de la preocupación ante la posibilidad de seguir el movimiento migratorio anterior ${ }^{46}$. La fundación de la Caja Vitícola en 1910 y el auge de los Sindicatos Agrícolas Católicos se deben apreciar también en este contexto. Uno de los objetivos fundamentales del catolicismo social fue el de crear o apoyar una amplia clase de pequeños agricultores/obreros, o sea, propietarios de pequeñas parcelas que, aparte de su propia producción, tenian que ganarse la vida con trabajo asalariado en las fincas de los grandes. Su función no se limitaba, por lo tanto, a frenar el movimiento obrero de tipo revolucionario, sino que perseguía además el objetivo de asegurarse un contingente estable de mano de obra barata y disponible para determinadas épocas del año, sobre todo desde el momento en que la situación del campo riojano tendio a mejorar.

\section{LA FILOXERA Y CAMBIOS ESTRUCTURALES}

Cuando la filoxera hizo su aparición en España, el sector agrario español se encontraba en una de las etapas más cruciales de su historia. La llamada crisis finisecular de la agricultura y el proceso de adaptación de la misma a las nuevas reglas del juego internacional, fueron una mezcla de crisis, modernización y adaptación más o menos dinámica a la nueva situación. Ello tuvo en muchos casos como último resultado el final de las estructuras tradicionales de un sector determinado. Si esta afirmación es cierta para la agricultura española en general, el sector vitivinícola no fue ninguna excepcion; sino al contrario, uno de sus sectores más dinámicos .

La destrucción del viñedo francés por la filoxera a partir de los años $70 \mathrm{del}$ siglo pasado tuvo un impacto muy fuerte en el sector vitivinícola español. La enorme demanda de vino común por parte de los vinateros franceses, que necesitaban los caldos españoles tanto para abastecer el mercado interior como para producir mediante el "coupage" los vinos destinados a sus mercados exteriores, produjo en España la que conocemos hoy como la edad de oro de la vinicultura española, aunque ésta pierde mucho de su resplandor al analizarla un poco más a fondo. En primer lugar, el «boom» exportador no llevó en la Península a una modernización del sector, aunque provoco un aumento sin precedentes de la superficie dedicada al cultivo de la vid. Una medida

46 Se trata de una serie de artículos que aparecian bajo el título «La Cuestión Social» en el periódico.

Hispania, LVU/2, núm. 193 (1996) 587-622 
extensiva, pues, a la que no tenía que seguir obligatoriamente una mejora en las técnicas del cultivo. Este hecho tiene también su explicación en las dificultades de mecanización en el cultivo de la vid. Para alcanzar una mejoría de la producciòn vitícola no hacían falta máquinas, sino un cultivo más cuidadoso, es decir, más horas de trabajo en los viñedos. Aun así tuvo lugar una serie de cambios técnicos, debidos a la aparición de nuevas enfermedades criptogámicas, como el ordio y el mildiu, que obligaron al uso de productos químicos en la viticultura.

Muy diferente se presenta la situación en la producción vinícola. Ahí sí que fue posible una industrialización, es decir, una mecanización mediante importantes inversiones en maquinaria y en la modernizacion de bodegas de tipo industrial. La mejora de la calidad de vino estaba estrechamente vinculada a la capacidad de inversión en tecnología vinicola más avanzada, que ya nada tenía que ver con la producción artesanal del propio viticultor.

Hechas estas observaciones, veamos ahora la relación entre la crisis filoxérica y los cambios estructurales en lá vitivinicultura española.

\section{IV.1. Provincia de Logroño}

En La Rioja, como en el resto de las provincias con cierto peso del sector vitivinícola, la crisis filoxérica fue precedida por una época enormemente beneficiosa para los viticultores, a su vez resultado de la filoxera, es decir, de su destructor paso por la vecina Francia. Entre 1870 y 1891 la superficie del vińedo riojano se duplic6 ${ }^{47}$, las exportaciones a la república vecina, favorecidas por la integración de la región en la red ferroviaria del Norte ${ }^{48}$, no dejaban de crecer y la euforia en el sector vitícola acallaba todos los problemas de los demás sectores agrarios sumergidos en una profunda crisis.

Pero la suerte no iba a ser duradera, como pronto lo avisaron algunas voces indicando que el fracaso estaba previsto si no se llegaba a una mejora de la calidad del vino riojano. Realmente, la evolución del sector vitivinícola riojano en la época del auge exportador fue muy problemática, como lo demuestran los siguientes hechos:

- Crecimiento extensivo e incontrolado del sector por una "fiebre» de plantar viñas que nada tomaba en consideración la calidad de los caldos, sino que iba dirigido exclusivamente hacia la producción de una mayor cantidad para poder satisfacer la enorme demanda de los franceses y optimar as los beneficios a corto plazo.

47 La superficie vitícola creció de 24.586 hectáreas (1855) a 34.380 hectáreas (1874) y alcanzó las 52.392 hectáreas en el año 1889; en: "Vinos y Aceites», núm. 41, febrero de 1878; Avance Estadístico sobre cultivos y producciön de la vid en España formado por la Junta Consultiva Agrono. mica 1889, Madrid 1891.

48 Delgado IDarreta, J. M., (1979), "La Rioja, Logroño y los ferrocarriles a fines del siglo xix», Cuademos de Investigación, Geografía e Historia, t. V, fasc. I, págs. 135-150.

Hispania, LVI/2, núm. 193 (1996) 587-622 
- Aumento del cultivo de la vid, con características de monocultivo, a costa de una agricultura más diversificada, sobre todo en la comarca de la Rioja Alta.

- Dependencia de un único mercado exterior, el francés, con pocas posibilidades de influir sobre él.

Vemos, pues, que el crecimiento del sector vitivinícola riojano provocado por el boom exportador se manifestó básicamente en un crecimiento del sector vitivinícola tradicional con pocas perspectivas para el futuro. Al mismo tiempo, presenciamos los primeros intentos tímidos de la alta burguesía riojana de emprender un camino de modernización de la producción vinícola, que se materializaron en las primeras bodegas «industriales" como las de Murrieta en Logroño o las de Riscal en Elciego.

A partir de 1887 los precios de los vinos riojanos empezaron a bajar. Se trata de los primeros sintomas de una crisis de sobreproducción, a pesar de la todavía inquebrantada demanda francesa. La decisión del gobierno francés en 1892, presionado por los propios viticultores, de gravar el vino espanol con unas tarifas aduaneras claramente proteccionistas tuvo en La Rioja dos consecuencias diametralmente opuestas. Por un lado hundió el sector vitivinícola tradicional en la mayor crisis de toda su historia; por otro, dio un fuerte empuje a la naciente industria vinatera de la élite riojana, que se beneficio claramente del hundimiento de los precios del vino y de la falta de competencia en los mercados interiores del vino de calidad francés.

Descubrimos, por lo tanto, una tendencia importantisima dentro de la vitivinicultura riojana antes de la invasión filoxérica. Se trata del comienzo de la lenta pero progresiva desaparición del vitivinicultor tradicional como único protagonista en el sector, y del surgimiento de una clara separacion entre la viticultura y una vinicultura dominada cada vez más por grandes bodegas modernas y altamente capitalizadas.

En relación con lo anterir se plantea la siguiente cuestión. A saber: si la crisis de la filoxera influyó en este proceso de separación entre viti y vinicultura. La respuesta es claramente afirmativa. El primer indicio lo encontramos en que la filoxera no parecia preocupar a los bodegueros riojanos en un grado muy alto. Cómo, si no, se explica la fundación de bodegas en un momento en que la invasión filoxérica ya era un hecho irrevocable ${ }^{49}$. Aparte de tener más recursos para afrontar la replantación en sus propios viñedos y de disponer de un stock de vino almacenado que ayud6 a superar el hueco provocado por la filoxera, la mayoría de las bodegas riojanas recurrieron a la importación de vino de otras zonas españolas como La Mancha, Cataluña, Valencia y Alicante. Se trataba, por lo tanto, de una respuesta al «estilo francés» por parte de las bodegas riojanas, es decir, la importación de vino desde fuera para utilizarlo como materia prima en las

49 Por ejemplo, las Bodegas Bilbaínas (1901) y la bodega de Angel Santiago (1904). 
técnicas del coupage y así garantizar el nivel de producción para el abastecimiento de sus mercados.

Cuanto más avanzaba la filoxera en La Rioja, mayor tenía que ser la cantidad importada, y cuando la produccion riojana empezó a recuperarse, las bodegas se habían independizado ya tanto del sector vitícola riojano, que siguieron comprando de fuera a pesar de la creciente producción interior. Lo que llevó a partir del año 1912 al conflicto abierto entre los viticultores, organizados en la Asociación de Viticultores Riojanos, y las bodegas, a su vez gremiadas en el Sindicato de Exportadores de Vino Rioja, dos organizaciones de grupos de interés que hasta ese momento habían unido en muchas ocasiones sus fuerzas para campañas conjuntas ${ }^{50}$.

Los viticultores que no habian manifestado ninguna resistencia contra las importaciones de vinos de otras provincias mientras el nivel de producción propia se encontraba a unos niveles muy bajos, al aumentarla ya no quisieron permitir esas prácticas y pidieron una especie de Consejo Regulador para controlar este asunto, dando prioridad a la producción riojana. Las bodegas, por otro lado, no tenían ningún interés en restricciones de este tipo, ya que para ellos la importación de vinos, en muchos casos más baratos y más homogéneos, no significaba sólo la solución más barata, sino también un importante instrumento de presión para mantener los precios de los caldos riojanos al nivel que a ellos les convenía.

Si hablamos de cambios estructurales tenemos que centrarnos también en otra cuestión, es decir, en la redimensión de la viticultura riojana. Esta claro que las 52.000 hectáreas de viñedo, una vez terminado el «boom» exportador, ya no tenían ningún sentido. La filoxera hizo lo que supuestamente hubiera ocurrido también sin ella, es decir, un fuerte reajuste de la superficie ocupada por la vid, aunque no de manera tan radical y con costos sociales tan elevados.

En cuanto a la distribución del viñedo replantado por distritos la siguiente tabla nos ilustra los cambios ${ }^{51}$ :

1902

$6,1 \%$

$6,2 \%$

$3,2 \%$

$8,4 \%$

$19,9 \%$

$18,6 \%$

$32.9 \%$

$4,7 \%$

$100,0 \%$
1922

$7,6 \%$

$8,1 \%$

$4,9 \%$

$9,3 \%$

$25,5 \%$

$14,8 \%$

$27,6 \%$

$2,1 \%$

$100,0 \%$

Total

50 Desartollado en OESTREICHER (1992), op. cit., págs. 100 y ss.

51 Elaboración propia, basándome en los datos de Proveno (1987), op. cit., págs. 158/199.

Hispania, LVI2, núm. 193 (1996) 587-622 
Constatamos, por lo tanto, que los distritos de la Rioja Baja y de la capital aumentaron, aunque no espectacularmente, su posición dentro del ámbito provincial, a costa de la Rioja Alta que perdió algo de su importancia vinf́cola. Aunque no se trata de cambios significativos en cuanto a valores numéricos, sí es sorprendente que en la zona con más densidad bodeguera, el distrito de Haro, el porcentaje sufrió un descenso de cinco puntos. La razón de esta tendencia a la baja está en el hecho de que la Rioja Alta fue la zona donde el predominio monocultivista del cultivo de la vid era más pronunciado. Es decir, que se trataba de una zona con pocos recursos procedentes de otros cultivos que hubieran podido financiar la replantación. La tendencia migratoria negativa nos confirma esta observacion.

Resumiendo lo precedente, podemos afirmar que la crisis filoxérica en La Rioja no fue la causa pero sí un importante catalizador de un cambio estructural en su vitivinicultura. Marco un punto final al sector vitivinícola tradicional en el que los viticultores habían sido también vinicultores, dejando a la producción artesanal de vinos únicamente los mercados más modestos, es decir, los de la misma provincia y de algunas zonas limítrofes. Al mismo tiempo, produjo una creciente divergencia entre los dos sectores, con claro dominio del sector bodeguero, al que los viticultores no consiguieron oponerse. Algunos intentos en este sentido fracasaron, como, por ejemplo, la fundación de una bodega cooperativa en Haro, impulsada por los Sindicatos Agrícolas Católicos ${ }^{52}$.

Es de suponer que sin la incidencia de la crisis filoxérica este proceso habría sido más lento, pero que también hubiera tenido lugar, ya que la sobreproducción en la provincia habria provocado una evolución con cambios. La reducción del viñedo riojano y la normalización de la producción vitícola después del paréntesis de la exportación a Francia se hubiera dado de todas las maneras, aunque no de manera tan traumática como la originada por la plaga filoxérica.

\section{IV.2. Andalucía}

El impacto de la filoxera en Francia sobre las exportaciones de Málaga fue mucho menos acentuado que en otras regiones vitivinícolas españolas. La razón fundamental de esta menor incidencia se encuentra en el mismo producto, es decir, el vino de Málaga, un vino generoso, dulce y con alta graduación alcohólica que nada tenía que ver con el vino común demandado por los vinateros franceses. La comercialización de este producto entro en los ańos 50 y 60 en una grave crisis, como ya hemos comentado, sobre todo por la reducción drástica de sus exportaciones a Inglaterra.

A partir del año 1873 las exportaciones malagueñas mostraron los primeros indicios de recuperación. Esta mejora estaba, sin embargo, sólo parcialmente

52 MEEs, L., (en preparación), Modernisierung und Interessenpolitik im spanischen Weinbau. Die Falle La Rioja und Navarra, pág. 132. 
ligada a la viticultura malagueña; aparte de una recuperación de la comercialización del vino Málaga, conseguida por el restablecimiento de la dañada imagen de este producto a través de un mayor control de calidad, empezaron a aumentar las exportaciones de vino común procedente de las provincias interiores expedidas por el puerto de Málaga con destino a Francia.

Detrás de este hecho se esconde una evolución que ya hemos descubierto en el caso de la Rioja. Se trata de la desconexión de la industria vinatera malaguefa del sector vitícola local, una tendencia que durante la filoxera se incrementó sustancialmente ${ }^{53}$. Los vinateros de la capital recurrieron cada vez menos a los viticultores de la zona para abastecerse de caldos y combinaron sus propias cosechas con vinos de otras provincias, como Valdepeñas - Montilla, más baratos para componer sus vinos y brandies, discriminando así en buena medida la producción de los viticultores locales. Desde esta perspectiva parece más lógico aún su desinterés en impulsar la replantación en la zona.

También en la región de Jerez de la Frontera podemos describir una evolución parecida. Entre 1850 y 1870 la fuerte demanda británica de vino «Sherry» favoreció a los cosecheros y almacenistas jerezanos que podían vender sus productos a precios cada vez más altos a las casas exportadoras. Pero solo durante algunos años, puesto que la respuesta de los comerciantes de vino no se hizo esperar. Empezaron a buscar los vinos en otras provincias, como Córdoba, Sevilla o Huelva, donde los consiguieron a precios mucho más bajos, y a fabricar sus vinos sin depender ya en buena medida de la producción vitícola jerezana. Esto significó un ataque frontal contra los intereses de almacenistas y cosecheros que, además, se vieron afectados gravemente por el descenso de las exportaciones a partir de 1873 provocado por problemas en el mercado ingless.

La confrontación continua entre los intereses de cosecheros, almacenistas y exportadores jerezanos se agudizó de manera rápida por la respuesta de los exportadores que intentaron salir de la crisis vendiendo vinos cada vez más jovenes y baratos, lo que afectó gravemente a los almacenistas, que se vieron ante la reducción de sus funciones. También entre los exportadores y los cosecheros aumentaron los problemas con la crisis, ya que los primeros estaban cada vez menos dispuestos a pagar un precio alto por los caldos de los cosecheros y presionaron a éstos mediante la importación de vinos de otras provincias. En otras palabras, las casas exportadoras tenían más medios para defenderse de la crisis que los otros dos grupos implicados en el comercio vinícola, convirtiendo sus casas en auténticas fábricas de vino que poco tenían que ver con el sector vitícola tradicional jerezano ${ }^{54}$.

La filoxera aumentó y aceleró estas tendencias con el resultado de acabar definitivamente con la viticultura tradicional jerezana. Por un lado, las casas exportadoras fueron los únicos representantes del sector vitivinícola jerezano

53 MORILLA (1988), op. cit., págs. 62 y ss.

34 CaBral (1987), op. cit. pág. 183.

Hispania, LVI/2, núm. 193 (1996) 587-622 
capaces de afrontar los gastos de la replantación, como ya hemos mencionado, y, por otro, podían suplantar la falta de vino de la propia zona mediante importaciones de otras provincias.

Hay otro dato importante que confirma estos cambios estructurales. El Sindicato de Viticultores constituido en 1894 para organizar la defensa contra la filoxera y apoyado en un principio por cosecheros, almacenistas y exportadores jerezanos evolucionó rápidamente en una dirección que poco interesó a los exportadores, es decir, hacia una plataforma que defendía los precios de uva y mostos jerezanos. Los exportadores se organizaron, por ello, a su vez, en la Compañía Vinícola Jerezana. Mientras que los cosecheros luchaban en favor de delimitar la zona vitícola jerezana para impedir la entrada de vinos forasteros, los exportadores defendían el establecimiento de una marca colectiva de Jerez para defenderse de la competencia extraprovincial. Pero se opusieron, lógicamente, a la delimitación geográfica para no impedir la introducción de vinos baratos y para no dejar que el cosechero vuelva a una situación ventajosa ${ }^{55}$. El paralelismo con lo ocurrido en La Rioja salta a la vista.

\section{IV.3. Cataluña}

Mientras que la modernización tecnológica en el proceso de la vinificación tanto en La Rioja como en Málaga y Jerez fue asumida únicamente por una élite burguesa y acompañada de un alejamiento progresivo entre vinicultura y viticultura, nos encontramos en Cataluña ante una situación muy distinta. En algunas zonas catalanas el cooperativismo agrario lleg6 a tener una importancia muy destacada y no se limitó, como en La Rioja, a la supervivencia de los viticultores mediante la adquisición colectiva de abonos, plantas y maquinaria agrícola y la propagación del crédito agrícola, sino que dio un paso más con una importancia trascendental: la fundación de bodegas cooperativas.

Es decir, que la cooperación entre los viticultores se extendio también a la producción y comercialización del vino. Así las bodegas cooperativas formaron un contrapeso muy importante frente a las bodegas capitalistas e impidieron a estas últimas el control absoluto sobre el proceso de la vinificación y comercialización.

¿Por qué funcionó el establecimiento de bodegas cooperativas en Cataluña y fracaso, mientras tanto, hasta la década de los 30 en La Rioja? Esta pregunta tiene que quedar abierta, por lo menos en el presente artículo. Se trata de un tema todavía poco estudiado, sobre el cual se podrían formular, como mucho, algunas hipótesis. Se ha de constatar que Cataluna en este aspecto representa una excepción dentro de las regiones que aquí hemos estudiado.

\footnotetext{
\$5 lbid., pág. 186.
} 


\section{v. CONCLUSIONES}

La crisis filoxérica y su impacto en el sector vitivinícola español es un tema histórico muy complejo que nos obliga a enfocarlo de manera amplia, situándolo en el marco de la historia socio-económica y agraria española finisecular. Sólo así será posible atribuir a la filoxera el lugar que le corresponde, sin exagerar ni menospreciar su importancia.

Al mismo tiempo el análisis sobre las consecuencias de la filoxera en España tiene que basarse en estudios regionales, puesto que, $-\mathrm{y}$ espero que el presente artículo lo haya puesto de manifiesto-, la diversidad entre las regiones vitivinícolas españolas es pronunciada y no permite generalizaciones superficiales.

Hemos intentado acercarnos a la crisis filoxérica enfocándola desde cuatro ángulos: la lucha antifiloxérica, los posteriores esfuerzos de replantación, su impacto social y los cambios estructurales relacionados con esta plaga. $Y$ hemos constatado mediante la comparación de tres regiones distintas que las consecuencias de la filoxera varian mucho de una a otra e incluso dentro de las mismas. ¿Cuáles son, por lo tanto, los principales factores a tener en cuenta?

En cuanto a la lucha contra la filoxera hemos visto que la coyuntura económica en que se encontraba la vitivinicultura de una región al ser invadida por la plaga es de suma importancia. No es lo mismo responder a la filoxera en un momento de crisis con los efectos de una descapitalización generalizada que en una época de auge en la que los incentivos económicos y el capital disponible para hacer frente a la crisis son considerables. Llama, sin embargo, la atención que el potencial conflictivo de las medidas defensivas contra la plaga, es decir, el arranque y la quema de las cepas afectadas, fue muy alto, tanto en regiones en pleno auge vitivinícola como en regiones donde dicho sector se hallaba en una profunda crisis. En el primer caso, que es el de algunas provincias catalanas, la hostilidad ante las medidas antifiloxéricas se observa en la negativa de los viticultores a sacrificar sus vinas en un momento que les estaban proporcionando unos ingresos altamente remunerativos. En el segundo caso, que es el de La Rioja, la propia crisis y la falta de perspectivas y de seguridad impidieron una mayor colaboración con las medidas antifiloxéricas.

Pero, aparte de los factores coyunturales, las medidas de lucha contra la plaga por sí solas ya fueron bastante delicadas y difíciles de poner en práctica. Contrario a las enfermedades criptogámicas de la vid como el Oídio o el Mildiu, frente a las cuales la iniciativa particular de cada viticultor bastaba para defender sus viñedos, una vez encontrado el producto para combatirlas, la lucha antifiloxérica no podía realizarse de manera individual. Fue preciso una acción conjunta, tanto a nivel estatal, como a nivel provincial o local. La

Hispania, LVI2, núm. 193 (1996) 587-622 
Ley contra la Filoxera, que fue la base teorica de estas medidas coordinadas, fracaso totalmente en su puesta en práctica. Fue una ley que superaba por mucho la capacidad de España, tanto a nivel organizativo, como a nivel económico. Como consecuencia, la lucha antifiloxérica quedo en manos de las provincias que actuaron según los intereses de sus élites, lo que, a su vez, llevó a conflictos inevitables. La cuestión de la indemnización de las cepas destruidas, que nunca llego a solucionarse de manera satisfactoria, jug6 un papel central en estos conflictos y, por lo tanto, en el fracaso de las medidas antifiloxéricas en toda la Península.

$$
* \star *
$$

Al no existir un insecticida eficaz contra la filoxera, el único remedio para superar la crisis filoxérica fue la replantación de viñedos mediante el injerto sobre cepas americanas, resistentes contra los efectos destructivos de dicho insecto. Los costes de esta medida fueron, por consiguiente, mucho más altos, ya que se trataba nada menos que de la repetición de las inversiones completas a unos precios aún más altos provocados por los mayores gastos de la plantación y cultivo de la vid americana.

También los esfuerzos de replantación estuvieron relacionados muy estrechamente con la situación y las perspectivas económicas del sector vitivinicola de cada región, provincia o localidad. El hecho de encontrarse la vitivinicultura de una region en una coyuntura positiva, es decir, en una situación de alta demanda de vino y con precios remunerativos, facilitaba mucho las inversiones necesarias para la replantación, puesto que existían medios económicos (ahorros) e incentivos económicos suficientes. La mejor prueba de ello, aunque no directamente relacionada con el vino sino con la producción de uva fresca, la encontramos en el caso de Almería, donde la crisis filoxérica coincidio con un importante auge exportador de este producto. Sin embargo, en muchas zonas coincidió con tendencias de una crisis pronunciada, sobre todo dentro del sector vitivinícola tradicional que sufría, entre otras, las consecuencias de la política proteccionista francesa y de un cambio estructural muy fuerte en los mercados del vino.

Menos afectada se veía la naciente industria vinatera que, por un lado, disponfa en la mayorra de los casos de los medios económicos necesarios para afrontar la replantación de sus extensos viñedos, y, por otro lado, podía introducir vino de otras provincias, muchas veces más baratos que los autóctonos, para realizar la técnica del coupage. El hecho de replantar o no lo tenemos que relacionar, además, con otros factores. Por ejemplo, la posibilidad de encontrar alternativas al cultivo de la vid influía mucho en la decisión sobre una eventual replantación. Es el caso de la naranja valenciana que, a pesar de las enormes diferencias en el cultivo, logró arrinconar la producción vitivinicola de la región.

Para los pequeños viticultores que por sí solos no podían afrontar los costes de la replantación, después de haber perdido toda su inversión, muchas veces incluso hipotecada, el apoyo tanto de las instituciones como 
de las élites economicas fue generalmente decisivo para poder reconstituir sus viñedos. Este apoyo, donde se daba, no tiene que ser interpretado como "regalo soliadario por parte de los más poderosos, sino que respondía a unos intereses claramente definidos. En Cataluña, por ejemplo, los nuevos contratos entre terratenientes y rabassaires, favorables en muchos aspectos a los últimos, incluía, a la vez, una ventaja a largo plazo muy importante para los primeros, es decir, la superación del contrato de la Rabassa Morta que tantos derechos había dado a los arrendatarios. En La Rioja la labor de los Sindicatos Agrícolas Católicos y la creación de la Caja Vitícola Provincial, por un lado, favorecía en gran medida a los pequeños viticultores que, con los «créditos blandos», pudieron replantar; por otro, sin embargo, era una necesidad primaria para las élites del sector que necesitaban la mano de obra barata y poco conflictiva de los pequeños propieatrios-braceros y que no podían permitir que siguiese la emigración. En Málaga, finalmente, donde la recuperación de los pequeños viticultores de la zona montañosa nada tenía que ver con los intereses de la burguesía de la Hoya y del Litoral, no se emprendió ningún esfuerzo para apoyar la replantación de los propietarios modestos.

El impacto social de la crisis de la filoxera se dejó notar en todas las regiones vitivinícolas españolas. Se evidencia en la creciente conflictividad social y en las tendencias migratorias provocadas por la ruina de muchos viticultores y obreros de campo. En cuanto a la conflictividad social, no podemos olvidar que ésta existía también antes de la filoxera. Pero sí hemos podido constatar en todas las regiones examinadas que ésta aumentó de modo importante y llegó a estallar abjertamente en algunos momentos. El caso de Cataluña, donde la filoxera hizo estallar un conflicto social latente - la cuestión rabassairenos puede servir como prototipo de esta cuestión. Pero también en La Rioja se empez6 a notar una conflictividad social creciente, sobre todo en los primeros años de la invasion filoxérica. Las numerosas huelgas de obreros agrícolas en los años de 1901/02 y, también, las movilizaciones por parte de los pequefios viticultores contra la asolución americana" de la crisis la indican claramente.

La emigración es otro fenómeno estrechamente relacionado con la crisis filoxérica. Para muchas personas, sobre todo pequeños viticultores y obreros de campo, la pérdida de sus medios de subsistencia no les dejaba otra salida. El destino de esta emigración siempre era el más cercano posible. Es decir, si dentro de la misma provincia hab́a posibilidades de encontrar un futuro económico, la emigración se desarrollaba en primer lugar dentro de la zona respectiva. Cuando esto no era posible, la emigración se dirigía a otras provincias, a otros países y, en muchos casos, a otros continentes. Por estas razones, en una provincia como Barcelona, con un sector industrial muy desarrollado, las posibilidades de encontrar un futuro, aunque a veces igual de precario, eran mucho mayores que, por ejemplo, en la provincia de Logroño. Dentro de la misma Rioja, la Rioja Baja ofrecía más posibilidades

Hispartia, LVI/2, núm. 193 (1996) 587-622 
alternativas que la Rioja Alta, por lo que el flujo emigratorio fue más pronunciado en la segunda comarca.

Dentro de los cambios estructurales que experimentó el sector vitivinícola español a finales del siglo XIX y principios del XX es, quizá, más difícil descubrir claramente el papel de la filoxera. La filoxera nunca fue causa de los cambios profundos dentro de este sector, pero sí influyó gravemente en la manera de producirse.

Lo que observamos a finales del siglo xix es una grave crisis estructural de la vitivinicultura tradicional, una vez terminado el gran «boom» exportador a Francia, que hasta finales de los años 80 había conseguido ocultar los problemas profundos de este sector. Estos se evidenciaron, sobre todo, en una grave crisis de sobreproducción, consecuencia de un crecimiento extensivo incontrolado del cultivo de la vid, a partir de 1885 , crisis que se acentuó desde el final del contrato comercial con el país vecino. El hundimiento de los precios, tanto de la uva como del mosto común, fue un hecho generalizado en toda la Península. La falta de mercados, la baja calidad del vino producido artesanalmente y los graves problemas de comercialización quedaron al descubierto una vez que se habían agotado las posibilidades casi ilimitadas de la exportación a Francia.

Al mismo tiempo presenciamos en loquas remper y provincias una

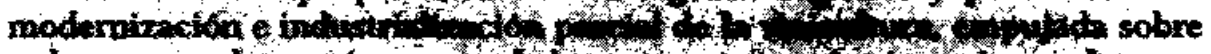

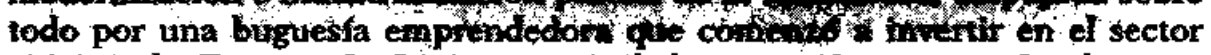
vitivinícola. Tanto en La Rjoja, a partir de los años 60, como en Cataluña, se fundaron grandes bodegas industriales con suficiente capital para enfrentarse a la nueva situación, mediante la mejora de la calidad de los vinos y estrategias de comercialización más eficaces. En Málaga y Jerez, donde ya existran potentes industrias vinateras, tatas, al veriso sus productos flos vinos secos y de alta graduación alcohólica de marca Malaga y Jerez) ante graves problemas de salida a los mercados, especialmente el mercado inglés, se adaptaron a la nueva situación mediante la venta de vinos de menor calidad, obtenidos parcialmente por la compra y mezcla de vinos procedentes de otras provincias.

El surgimiento de un sector vinícola moderno fue arrinconando muy pronto la producción vinícola artesanal y reduciendo el papel de los vitivinicultores tradicionales al de meros suministradores de materia prima, fuera de mosto $o$ de uva. Las bodegas, a partir de 1892, viéndose ante unas condiciones 6ptimas por los bajos precios del vino y la uva, empezaron, como únicos compradores importantes, a dominar claramente el sector vitivinícola de su region.

Tampoco la filoxera y la caída de la producción de uva pudieron cambiar esta nueva jerarquía, ya que fueron en muchos casos los bodegueros los primeros en replantar los vifiedos destruidos y, además, no dudaron en importar vinos de otras regiones españolas que todavía no habían sido afectadas por la plaga, siguiendo así claramente el ejemplo francés.

Hispania, LVI/2, núm. 193 (1996) 587-622 
Si la filoxera no fue responsable de los cambios estructurales en el sector vitivinícola español, sí que apoyó este proceso directa e indirectamente. Aceleró de manera brutal, y socialmente costosísima, la redimensión necesaria del área de vifiedo en la Península, aunque no pudo evitar que a partir del fin de la Seguna Guerra Mundial la sobreproducción se dejara notar de nuevo. Al mismo tiempo, fortaleció en gran medida a la nueva élite vitivinícola, no tanto por la desaparición de la viticultura tradicional —que recuperó mucha importancia en la mayoría de la regiones estudiadas, excepto quizás la zona de Jerez donde las tendencias de concentración de la propiedad vitícola estaban más acentuadas - sino por el creciente predominio del sector moderno frente a ella. La progresiva independencia de las bodegas respecto a la producción viticola regional, experimentada en la época de la crisis filoxérica por la importación de vino de otras provincias, resultó en beneficio del sector moderno. La compra de vino de fuera, sobre todo de vino barato, como por ejempo de La Mancha, no sólo garantizaba a las bodegas la materia prima en tiempos de una oferta regional reducida, sino que también les servia como un instrumento sumamente eficaz para controlar y mantener a la baja los precios de la producción local y regional. Esto lo entendemos cuando constatamos que muchas bodegas riojanas, por ejemplo, seguían introduciendo «foudres * de vino procedentes de Valdepeñas aun cuando la producción riojana ya se había recuperado, hecho denunciado y combatido duramente por la Asociación de Viticultores. Solo la organización de los viticultores en cooperativas de producción y comercialización podía suponer un contrapeso a esta evolución, intento que en muchas regiones fracasó y que sólo en Cataluña tuvo cierto éxito.

\section{BIBLIOGRAFIA}

Balcells, A., (1980), El problema agrario en Cataluña. La cuestión Rabassaire (1890-1936), Madrid.

Balcells, A., (1977), «La conflictividad social agraria en Cataluña y la Unió de Rabassaires hasta 1939 y, Agricultura y Sociedad, núm. 2, págs. 347-396.

Cabral Chamorro, A., (1987), «Observaciones sobre la regulación y ordenación del mercado del vino en Jerez de la Frontera 1850-1935; los antecedentes del consejo regulador de la denominación de origen Jerez - Xérès Sherry", Agricultura y Sociedad, núm. 44, julio/sept., págs. 171-191.

Calatayud, S., (1989), Capitalismo agrario y propiedad campesina, La Ribera de Xúquer (Valencia) 1860-1930, Valencia.

Carnero i Arbat, T., (1980), Expansión vinicola y atraso agrario, Madrid. Guisado López, J.M., (1983), «Crisis agraria e invasión filoxérica en la España del siglo XIX», Revista de Historia Económica, año I, núm. 2, págs. 165-184.

Hispania, LVI/2, mưm. 193 (1996) 587-622 
Delgado Idarreta, J.M., (1979), "La Rioja, Logroño y los ferrocarriles a fines del siglo xIX», Cuadernos de Investigación, Geografía e Historia, t.V, fasc. I, págs. 135-150.

Ferrer i Alós, L., (1991), «La pequeña explotación en un viñedo de la Cataluña Central en los siglos XIX y XX. Consideración sobre su evolución y comportamiento», en: Saavedra, P.Nillares R., (eds.), Señores y campesinos en la península iberica, siglos $X V I I-X X, \mathrm{t} .2$, Campesinado y pequeña explotación, Barcelona, págs. $34-62$.

Gallego Martínez, D., (1986), La producción agraria de Alava, Navarra y La Rioja, (tesis doctoral), Madrid, pág. 925.

Iglesies, J., (1968), La crisi agrária de 1879/1900: La filoxera a Catalunya. Barcelona.

Mees, L., (en preparación), Modernisierung und Interessenpolitik im spanischen Weinbau. Die Fälle La Rioja und Navarra.

Morilla Critz, J., (1988), «Las condiciones de comercialización de los productos vitícolas y respuesta a la filoxera en Andalucía Oriental (1873 - 1914)», Revista de Estudios Regionales, núm. 20, págs. 57-77.

Morilla Critz, J., (1989), Cambio en la viticultura de Andalucía Oriental durante la crisis de finales del siglo XIX. Estudio sobre los datos de los informes consulares británicos», Revista de Historia Económica, núm. 1, págs. 157-197.

Muffoz del Castillo, J., (1878), La plaga filoxérica. Logroño.

Oestreicher, A., (1992), Die Reblausplage in der spanischen Region La Rioja Sozial- und wirtschaftsgeschichtliche Untersuchung des Weinsektors der spanischen Region La Rioja zwischen 1860 und 1915. Zürich (Memoria de licenciatura inédita).

Oestreicher, A., «Algunos aspectos de la historia del sector vitivinícola riojano, 1860-1915; en: Berceo.

Palafox Gamir, J., (1987), «Exportaciones, demanda interna y crecimiento económico en el País Valenviano», en: Sánchez Albornoz, N., (ed.), La modernización economica de España 1830-1930, Madrid: Alianza, págs. 319-343.

Piqueras, J., (1985), La agricultura valenciana de exportación y su formación historica, Madrid: Serie Estudios Agrarios, Pesqueros y Alimentarios.

Pellejero Martínez, C., (1988), «Decadencia del viñedo y crisis poblacional en la Málaga de finales del siglo XX” " Revista de Historia Económica, año VI, núm. 3, págs. 593-633.

Pellejero Martínez, C., (1986), «La crisis agraria a finales del siglo XIX en Málaga, Revista de Historia Económica, núm. 3, págs. 549-589.

Pouget, R., (1990), Histoire de la lutte contre le Phylloxera de la vigne en France. Versailles: Institut Nacional de la Recherche Agronomique.

Provedo González, J., (1987), "La filoxera en la provincia de Logroño (Destrucción del vifiedo y su reconstitución)», Zubta, núm. 5, págs. 151-216.

Pujol Andreu, J., (1986), "La crisis de sobreproduccion en el sector vitivinícola catalán, 1892-1935», en: Garrabou, R./Barciela, C./Jiménez Blanco, J., (eds.), Historia agraria de la España contemporánea, t. 3, El fin de la agricultura tradicional (1900-1960), Barcelona: Crítica, págs. 317-346.

Hispania, LVI/2, núm. 193 (1996) 587-622 
Simpson, J., (1985), «La producción de vinos en Jerez de la Frontera 18501900», en: Martín Aceffa, P./Prados de la Escosura, L., (eds.), La nueva historia económica en España, Madrid: Tecnos, págs. 166-191.

Zoido Naranjo, F., (1980), «Observaciones sobre la crisis filoxérica y sus repercusiones en la vitivinicultura de Jerez», Archivo Hispalense, núm. 193/94, págs. 487-507. 